This item was submitted to Loughborough's Research Repository by the author.

Items in Figshare are protected by copyright, with all rights reserved, unless otherwise indicated.

\title{
Elastohydrodynamic lubrication of hypoid gear pairs at high loads
}

PLEASE CITE THE PUBLISHED VERSION

http://dx.doi.org/10.1177/1350650111431027

PUBLISHER

(c) Sage

VERSION

AM (Accepted Manuscript)

LICENCE

CC BY-NC-ND 4.0

REPOSITORY RECORD

Mohammadpour, Mahdi, Stephanos Theodossiades, and Homer Rahnejat. 2019. "Elastohydrodynamic Lubrication of Hypoid Gear Pairs at High Loads". figshare. https://hdl.handle.net/2134/13317. 
This item was submitted to Loughborough's Institutional Repository (https://dspace.lboro.ac.uk/) by the author and is made available under the following Creative Commons Licence conditions.

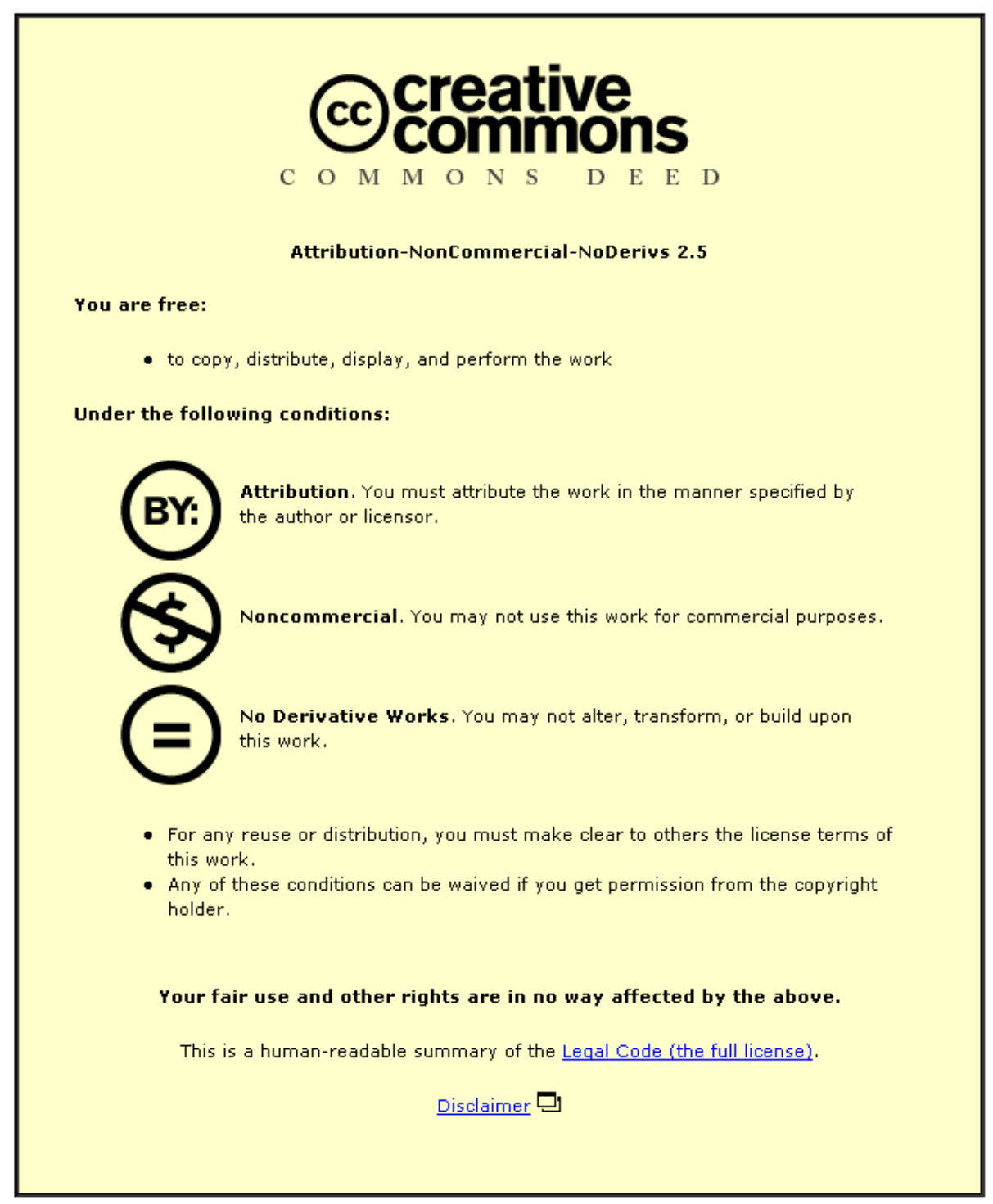

For the full text of this licence, please go to: http://creativecommons.org/licenses/by-nc-nd/2.5/ 


\title{
Elastohydrodynamic lubrication of hypoid gear pairs at high loads
}

\author{
M. Mohammad-Pour, S. Theodossiades and H. Rahnejat* \\ Wolfson School of Mechanical \& Manufacturing Engineering \\ Loughborough University, Loughborough, UK \\ *corresponding author: H.Rahnejat@Lboro.ac.uk
}

\begin{abstract}
Differential hypoid gear pairs have been the mechanism of choice for high torque capacity final drives in all forms of vehicles, at least since mid $19^{\text {th }}$ century. Transmission efficiency as well noise and vibration concerns require combined elastohydrodynamic and tooth contact analysis of hypoid gear teeth pairs through mesh. Although such analyses have been reported for general cases of elliptical point contact conjunctions with angled flow entrainment, they do not comply with the prevailing load and kinematic conditions in differential gears. In particular, teeth pair contacts are subject to significant loads of order of several $\mathrm{kN}$ requiring solution to the EHL problem at such high loads. The current analysis reports solutions for rolling and sliding elastohydrodynamics of hypoid gear teeth pairs at realistic drive torques, not hitherto reported in literature.
\end{abstract}

\section{Keywords: Hypoid gears, Elastohydrodynamics, Tooth Contact Analysis, Elliptical point contact, Angled entrainment flow}

\section{Nomenclature}

a : Contact semi-major half-width

$b \quad$ : Contact semi-minor half-width

$E_{p} \quad$ : Young's modulus of elasticity of pinion gear material

$E_{r} \quad:$ Reduced elastic modulus of the contact: $\pi /\left(1-v_{p}^{2} / E_{p}\right)+\left(1-v_{w}^{2} / E_{w}\right)$

$E_{w} \quad$ : Young's modulus of elasticity of gear wheel material

F : Contact load per meshing pair (obtained through tooth contact analysis)

$G^{*} \quad$ : Material's parameter

h : Film thickness

$h_{c 0} \quad:$ Central contact film thickness

$h_{c 0 \infty} \quad$ : Central film thickness at the inlet meniscus for flooded condition

$h_{m} \quad$ : Minimum film thickness

$h^{*} \quad:$ Dimensionless film thickness

$m \quad$ : Inlet boundary parameter

$m^{*} \quad$ : Starvation demarcation boundary parameter 
$n_{g}, n_{p}:$ Unit vectors along the gear wheel and the pinion gear axes

$n_{\text {major }}, n_{\text {minor }}$ : Unit vectors along the major and minor axes of the elliptical footprint

p : Pressure

$r_{p} \quad:$ Radius of pinion gear tooth in the $z x$ plane of contact

$r_{w} \quad$ : Radius of gear wheel tooth in the $z x$ plane of contact

$R_{\text {gear }} \quad$ : Position vector of the contact point from the gear wheel axis

$R_{p} \quad$ : Radius of pinion gear tooth in the zy plane of contact

$R_{\text {pin }} \quad$ :Position vector of the contact point from the pinion axis

$R_{w} \quad$ : Radius of gear wheel tooth in the zy plane of contact

$R_{z x} \quad$ : Equivalent radius of contact along the direction of minor axis of elliptical footprint

$R_{z y} \quad$ : Equivalent radius of contact along the direction of major axis of elliptical footprint

$s \quad$ : Contact profile of the equivalent ellipsoidal solid

$U \quad$ : Speed of entraining motion

$U^{*} \quad$ : Speed (Rolling viscosity) parameter

$v_{g}, v_{p}$ : Spatial velocity of points of contact on gear wheel and on the pinion

$v_{g}^{n}, v_{p}^{n}:$ Normal components of $v_{g}, v_{p}$

$v_{g}^{t}, v_{p}^{t}$ : Tangential (surface) components of $v_{g}, v_{p}$

$v_{g}^{t, \text { major }}, v_{p}^{t, m a j o r}$ : Components of $v_{g}^{t}, v_{p}^{t}$ along the major axis of the elliptical footprint

$v_{g}^{t, \text { minor }}, v_{p}^{t, \text { minor }}:$ Components of $v_{g}^{t}, v_{p}^{t}$ along the minor axis of the elliptical footprint

W : Calculated contact load (integrated pressure distribution)

$W^{*} \quad$ : Load parameter

$x \quad$ : Direction/distance along the minor axis of the elliptical footprint

$y \quad$ : Direction/distance along the major axis of the elliptical footprint

$x_{c}, y_{c}$ : Lubricant film rupture boundaries along minor and major axes of the elliptical footprint

Z $\quad$ : Orthogonal direction to the plane of contact

\section{Greek Symbols:}

$\alpha \quad$ : Lubricant pressure-viscosity coefficient

$\delta \quad:$ Contact deflection

$\varepsilon_{p} \quad:$ Error in pressure convergence

$\varepsilon_{w} \quad:$ Error in load convergence

$\eta \quad$ : Lubricant dynamic viscosity at pressure $p$

$\eta_{0} \quad$ : Lubricant dynamic viscosity at atmospheric pressure

$\varphi \quad$ : Pinion angle

$\theta \quad:$ Angle of lubricant entrainment into the contact 


$$
\begin{array}{ll}
\lambda & : \text { Stribeck's oil film parameter } \\
\rho & : \text { Lubricant density at pressure } p \\
\rho_{0} & \text { : Lubricant density at atmospheric pressure } \\
\sigma_{r m s} & \text { : Root mean square of composite surface roughness } \\
\varsigma & : \text { Film relaxation damping factor } \\
v_{p} & \text { : Poisson's ratio of the pinion gear material } \\
v_{w} & \text { : Poisson's ratio of the gear wheel material } \\
\omega_{g} & : \text { Angular velocity of the gear wheel } \\
\omega_{p} & : \text { Angular velocity of the pinion gear } \\
\Omega & : \text { Pressure under-relaxation factor }
\end{array}
$$

\section{Introduction}

It is claimed that the history of differential gears goes back to at least $1050 \mathrm{BC}$ where reference is made in the Chinese Book of Song (479-420 BC) to their use in the South Pointing Chariot of Liu Song Dynasty. However, modern automotive differential gears used today are evolutions of the bevel gear pairs patented in Paris in 1827 by Onésiphore Pecqueur. The English bicycle entrepreneur, James Starley used a version of this in a chaindriven form in 1876. This paved the way for its inclusion in the very first 3-wheeled car built by Karl Benz in 1885. Ever since, differential gear pairs with their orthogonal axes have become the final drive feature in all vehicles. The high load carrying capacity usually required of the final drive constitutes partially conforming meshing teeth pairs. This requirement brings about the hypoid gear pair geometry, which also presents gradual changes in geometry of an elliptical contact footprint. The hypoid gear teeth pairs form elliptical contact footprints and are often subject to high loads of the order of several $\mathrm{kN}$. The differential gear pair also enjoys a lower transmission error than other forms of gearing and thus runs rather silently. Relatively low engine torques at higher engine speeds are increased at the expense of the angular momentum resident on the pinion gear.

Studies of elliptical point contacts commenced after the pioneering paper on elastohydrodynamic lubrication (EHL) by Grubin (1949), based on his work with Ertel (1939). In fact, Grubin provides a film thickness equation based on his analytical solution of circular point contact EHL. The equation takes into account the effect of contact load, surface velocities and lubricant rheological parameters; viscosity and pressure-viscosity coefficient. However, it ignores the side leakage from the contact, requiring a correction factor which has been described by Gohar (2001). Although, this equation is used successfully in many industrial applications, it only provides an estimate of the thickness of a flat film, not the minimum film thickness which is in the vicinity of the pressure spike at the exit from an EHL conjunction. The study of film shape was carried out later through optical interferometry by Gohar and Cameron (1963). Numerical work on EHL, first undertaken by Dowson and Higginson (1959) for infinite line contact, was extended by Archard and Kirk (1961), Archard and Cowking (1965) and Cameron and Gohar (1966) to the case of point contacts, 
predictions of the last of which agreed well with their earlier interferometric studies. The numerical analyses was further refined and extended to elliptical footprint geometries. The volume of simulation results yielded extrapolated oil film thickness formulae in terms of contact geometry, material and lubricant properties as well as load and contact kinematics. These expressions were obtained for the minimum film thickness at the exit constriction from the contact. The early contributions include those of Archard and Cowking (1965), Cheng (1970), Ranger et al (1975) and Hamrock and Dowson (1976a, 1976b). Others obtained extrapolated oil film thickness equations through optical interferometric studies. These include the studies by Westlake and Cameron (1973) for elliptical point contacts and that of Jackson (1973) who revised the work of Westlake.

Although these earlier equations are still in use in academe and industry to provide a quick estimate of lubricant film thickness, there are a number of shortcomings associated with them. Firstly, the range of operating parameters used, such as load and speed based on the original simulated results are somewhat limited due to difficulties in computation resources and stability of method of formulation and solution at the time. Method of solution was largely based on Voghpol transformation of Reynolds equation with Gauss-Seidel iterations and over-relaxation, which is only suitable for light to medium loads. Secondly, the earlier analyses excluded certain salient practical features, including inlet boundary starvation, lubricant flow at an angle to the elliptical contact footprint and the effect of squeeze film motion, all of which are essential for estimation of lubricant film thickness in hypoid gear teeth pair contacts. Relevant correction factors to take into account the effect of starvation was presented for numerical predictions by Hamrock and Dowson (1977) and by Wedeven et al (1971) through optical interferometry. With regard to the directional lubricant flow into an elliptical point contact conjunction, Mostofi and Gohar (1982) provided numerical predictions as well as extrapolated film thickness equations for both the central flat and the minimum exit constriction films. Furthermore, for the first time they included the effect of squeeze film action in their numerical analysis. At the time, the insufficient computational resource and method of solution (see above) impeded convergence at very high contact loads or transient analyses which are necessary for hypoid gear teeth pair contacts through mesh. Squeeze film action in Mostofi and Gohar (1982) represents a quasi-steady analysis as a series of arbitrarily chosen squeeze film velocities were used, rather than those which would be experienced in transient dynamics as described by Gohar and Rahnejat (2008). Nevertheless, their predictions agreed very well with the interferometric studies of Gohar (1971) for angled surface flows in elliptical point contacts under combined rolling and sliding conditions.

At high loads and under steady state entraining motion an inverse solution to the EHL problem was presented by Evans and Snidle (1982), who employed their approach for the elastohydrodynamic analysis with the rolling velocity vector coinciding with the major axis of the elliptical contact footprint. This condition is prevalent in highly loaded contact of Wildhaber-Novikov gears, used for example in some helicopter transmissions (Evans and Snidle, 1983). The results obtained by them shows that the film thickness is in fact one-third of the value which would be predicted by Mostofi and Gohar's extrapolated oil film thickness 
equation. Therefore, although the oil film thickness equations are readily used in combined dynamics and tribological studies (Rahnejat and Gohar, 1985, Rahnejat, 1985, Mehdigoli et al, 1990, and De la Cruz et al, 2010), care should be taken that extrapolation with these equations remain within the range of their original parametric studies.

With the use of better solution methods such as the effective influence Newton-Raphson (EIN) low relaxation method and multi-level multi-grid techniques, elastohydrodynamic lubrication problems at high loads and under transient conditions, including the effect of squeeze film action have been reported. Some initial contributions are due to Dowson and Ehret (1999), Ehret et al (1997), Venner and Lubrecht (2000a, 2000b), and Jalali-Vahid et al, 1998a, 1998b, 2000, 2001). Since the original contribution by Mostofi and Gohar (1982), solutions taking into account combined rolling and sliding elliptical point contact EHL with directional lubricant entrainment into the contact include those by Chittenden et al (1985), who provided extrapolated oil film thickness formulae along the major and minor axes of the elliptical point contact footprint. More recent solutions by Jalali-Vahid et al (1998a, 2000) showed very good agreement with interferometric studies of Gohar (1971) and extended the solution to high loads and low speeds of entraining motion, thus providing a large range of operating conditions. This analysis showed that extrapolated equations of Mostofi and Gohar (1982) and Chittenden et al (1985) provide good agreement with numerical predictions at moderate loads and begin to deviate from the numerical solutions at loads exceeding several hundred N. This is in line with the same significant deviations noted between numerical results of Evans and Snidle (1983) with such extrapolated equations.

In gear applications and especially in hypoid gears, it is necessary to compute the principal radii of curvature of the pinion and gear wheel teeth through mesh. One method of achieving this is through tooth contact analysis (TCA). The method is outlined in detail by Litvin and Fuentes (2004). At any instant of time in differential hypoid gears several teeth pairs are in contact in order to carry the high torques generated. TCA calculates the load share per pair of teeth during any meshing cycle as well as the corresponding meshing stiffness and the static transmission error. Using this approach all alignment, manufacturing and assembly errors can be accommodated.

Some representative literature for TCA, for which there have been many, include the work of Litvin and Fuentes (2004) for the design of low noise spiral bevel gears, as well as investigating meshing of face-milled spiral bevel gears. Subsequently, finite element analysis was employed to determine the contact stresses of TCA-defined conjugate contacting surfaces (Litvin et al, 2002). Simon (2009a) presented a method to obtain the optimal tooth modifications for head-cutter spiral bevel gears. Recently, Kolivand and Kahraman (2009) presented a different approach to TCA, termed ease of topology method.

EHL and thermal EHL analyses represent one of the main applications of TCA. Xu and Kahraman (2007) and Kolivand et al (2010) have investigated mechanical inefficiencies in gearing arising from the EHL of meshing gear pairs, where a line contact approximation is made with flow along the contact width. Simon (2009b) presented a thermo- 
elastohydrodynamic analysis of hypoid gear pairs with point contact geometry, but at relatively low input torque, not representative of vehicle differentials. Again, the flow vector is assumed along the minor axis of the contact ellipse, this being a shortcoming as experimental evidence, for example by Gohar (1971) and numerical work by Chittenden et al (1985) and Jalali-Vahid et al (2000) suggest significant side-leakage flow along the major axis of the contact ellipse. The repercussion is that continuity of flow would be breached, as well as errors introduced in evaluation of contact temperatures due to the side leakage flow. Assumption of line contact footprint can be considered as reasonable in circumstances which promote an elliptical point contact of large aspect ratio. Thus, the works of $\mathrm{Xu}$ and Kahraman (2007) and Kolivand et al (2010) and that of Simon (2009b) have progressed the applications of EHL to proper gear meshing problems determined through TCA, where for completeness of the solution an elliptical contact condition is assumed at relatively low contact loads.

The current paper uses TCA (based on the approach of Vijayakar (2000) and Xu and Kahraman, 2007 ). This is to obtain instantaneous contact geometry, sliding velocity and load share per teeth pair for simultaneous meshing of 1-3 pairs of teeth in a light truck differential. These are input to an isothermal EHL solution of hypoid gear pairs. Realistic engine torquespeed characteristics are used, for instance an engine torque of $175 \mathrm{Nm}$ at $1852.5 \mathrm{rpm}$. For these conditions load share for teeth pair contacts are in the region of 500-6000 N. Therefore, a suitable method of solution is the distributed line low relaxation effective influence Newton-Raphson method. This method was used for ball bearings by Venner and Lubrecht (2000a, 2000b) and Jalali-Vahid et al (2000, 2001) for elliptical contacts with angled flow, but in both cases for moderate loads.

Hitherto, solution of elliptical point contact EHL for hypoid differential gears at high loads with lubricant angled flow has not been reported in literature and constitutes the major contribution of this paper to the evolving knowledge.

\section{Theoretical Model}

The method used is a two stage process, combining TCA and EHL analyses. The former determines at any instant of time, the number of teeth pairs in contact, their principal radii of curvature at their point of contact, the elastostatic elliptical contact footprint, surface velocities and load share for any conjugate mating teeth pair. These form the input to the elastohydrodynamic analysis.

\section{1- Elastohydrodynamic Analysis}

Pressures generated in a lubricated conjunction are obtained through use of Reynolds (1886) equation. The form of equation suitable for lubricant entrainment at any angle $\theta$ to the minor axis of an elliptical contact footprint is (figure 1): 
$\frac{\partial}{\partial x}\left[\frac{\rho h^{3}}{\eta} \frac{\partial p}{\partial x}\right]+\frac{\partial}{\partial y}\left[\frac{\rho h^{3}}{\eta} \frac{\partial p}{\partial y}\right]=6 U\left\{\cos \theta \frac{\partial}{\partial x}[\rho h]+\sin \theta \frac{\partial}{\partial y}[\rho h]\right\}$

The speed of entraining motion of the lubricant $U$ through the contact is considered to be constant at any instant of time. Any localised changes in the speed of entraining motion due to angled flow are considered small due to the minute contact footprint size. In reality, there will be small variations along the contact footprint. However, the rate of change of lubricant entrainment velocity is small compared with the rates of change of the principal radii of curvature through mesh. In fact Reynolds equation, based on laminar flow, assumes an instantaneous steady speed of entraining motion. The form of Reynolds equation (1) omits the squeeze film effect as the result of approach and separation of gear teeth pairs. This is a transient effect which often increases the load carrying capacity of the contact as noted by Gohar and Rahnejat (2008).

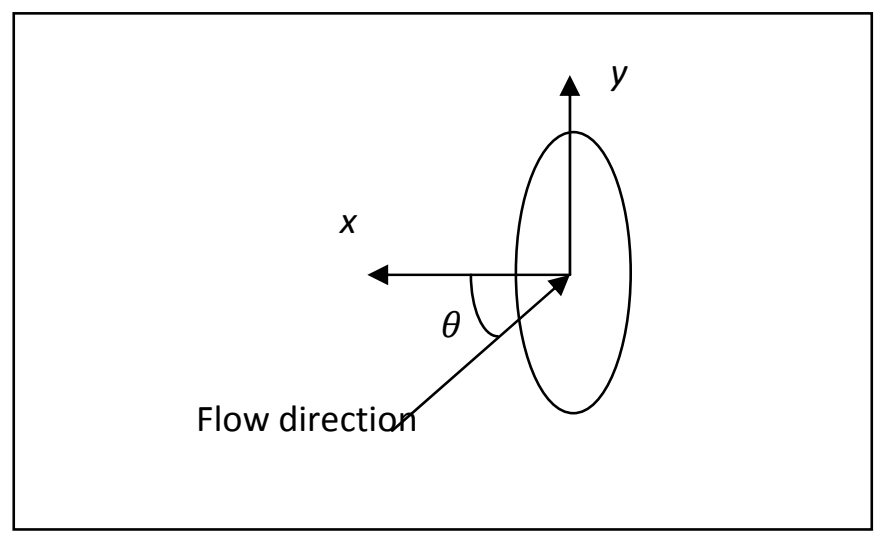

Figure 1: Representation of an elliptical point contact conjunction with angled entrainment flow

The omission of squeeze film term in Reynolds equation renders a series of quasi-static solutions as opposed to transient analysis through gear teeth pair mesh. Film thickness at any spatial location within the contact domain is given by:

$h(x, y)=h_{c 0}+s(x, y)+\delta(x, y)$

where, the undeformed parabolic conjunctional profile is: $s(x, y)=\frac{x^{2}}{2 R_{z x}}+\frac{y^{2}}{2 R_{z y}}$

$R_{z x}$ and $R_{z y}$ are the equivalent radii of contact of an ellipsoidal solid against a semi-infinite elastic half-space, representing the instantaneous contact of any pinion to gear wheel teeth pair in the planes $z x$ (along the minor axis of the contact ellipse) and zy (along its major axis, figure 2):

$\frac{1}{R_{z x}}=\frac{1}{r_{p}}+\frac{1}{r_{w}}$ and $\frac{1}{R_{z y}}=\frac{1}{R_{w}}-\frac{1}{R_{p}}$ 
The instantaneous radii of pinion and gear teeth are determined through TCA (Vijayakar, 2000, Litvin et al, 2004, and Xu and Kahraman, 2007).

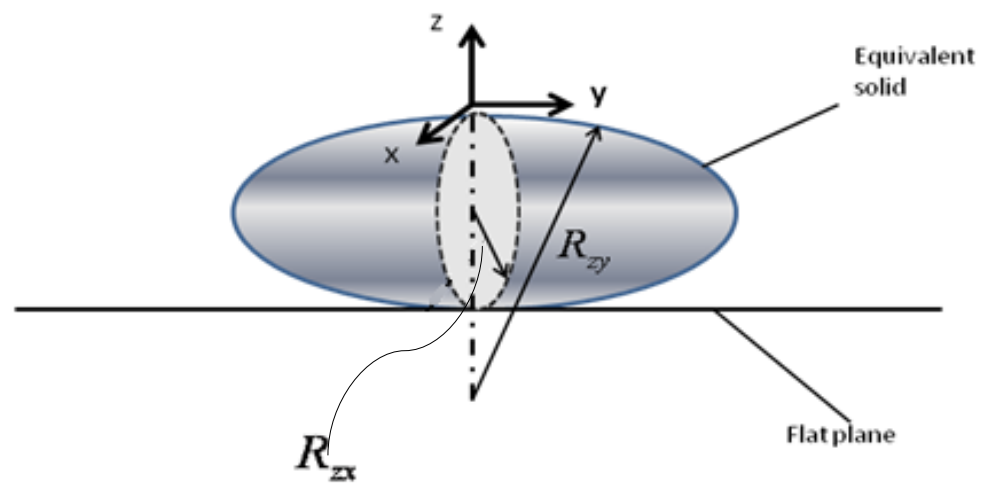

Figure 2: Contact Geometry of the equivalent ellipsoidal solid

The localised contact deflection $\delta(x, y)$ is obtained by solution of the elasticity potential integral:

$\delta(x, y)=\frac{1}{E_{r}} \iint_{A} \frac{p\left(x_{1}, y_{1}\right) d x_{1} d y_{1}}{\sqrt{\left(x-x_{1}\right)^{2}+\left(y-y_{1}\right)^{2}}}$

where, $(x, y)$ represents a point where deflection of the semi-infinite elastic half-space of reduced elastic modulus $E_{r}$ is calculated due to any arbitrary pressure distribution $p\left(x_{1}, y_{1}\right)$.

To obtain a solution to the EHL problem, comprising equations (1)-(4), the lubricant rheological state is required:

For piezo-viscous lubricant behaviour (Roeland, 1966):

$$
\eta=\eta_{0} \exp \left\{\left[\left(\ln \eta_{0}+9.67\right) \times\left(1+5.1 \times 10^{-9} p\right)^{Z}\right]-\left[\ln \eta_{0}+9.67\right]\right\}
$$

where:

$$
Z=\frac{\alpha c_{p}}{\left(\ln \eta_{0}+9.67\right)}=\frac{\alpha}{5.1 \times 10^{-9}\left(\ln \eta_{0}+9.67\right)}, \text { as } c_{p}=1.96 \mathrm{MPa}
$$

For lubricant density (Dowson and Higginson, 1959):

$$
\rho=\rho_{0}\left(1+\frac{0.6 \times 10^{-9} p}{1+1.7 \times 10^{-9} p}\right)
$$




\subsubsection{Boundary Conditions}

It is usual to assume a drowned or fully flooded inlet boundary condition in numerical analysis of EHL problems. In order to ensure this, the following conditions should be met: $x \rightarrow-\infty, p \rightarrow 0$ and $y \rightarrow-\infty, p \rightarrow 0$. This means that the inlet boundary should be set a suitable distance from the leading edge of the elliptical contact footprint. In numerical analysis a distance of 4-5 times the contact footprint semi-half-widths are chosen for this purpose (Hamrock and Dowson, 1976a, 1976b). The inlet distance changes with load in both directions; $m=x / b$ or $y / a$. Furthermore, the starvation boundary is also a function of height of the lubricant film at an assumed far distant inlet meniscus; $h_{c o s}$, which affects the central film thickness within the contact, $h_{c o}$ as a function of speed of entraining motion. Birkhoff and Hays (1963) determined the starvation boundary as: $h_{c o s} / h_{c o}=11.293$. Therefore, the inlet boundary parameter; $m$ must vary according to load and speed combination so that just flooded conditions are satisfied through mesh. This means that $m$ should be set at the socalled starvation boundary; the demarcation line between flooded and starved conditions. This is not often taken into account in the reported literature. Here, the starvation boundary parameters obtained numerically by Hamrock and Dowson (1977) and experimentally through optical interferometric studies by Wedeven et al (1971) are used:

Hamrock and Dowson (1977): $m^{*}=1+3.06\left[(R / \gamma)^{2} h_{c 0}\right]^{0.58}$

Wedeven et al (1971): $m^{*}=1+3.52\left[(R / \gamma)^{2} h_{c 0}\right]^{2 / 3}$

where for the flow component along the minor axis: $R=R_{z x}, \gamma=b$, and for that along the major axis: $R=R_{z y}, \gamma=a$.

In fact, these boundary lines yield quite similar results as shown for the contact of a pair of teeth through mesh in the differential hypoid gears used in the current study (figure 3 ). Thus, the inlet condition is set as $m=m^{*}$ using Hamrock and Dowson's starvation boundary. The procedure requires an initial estimation of the central oil film thickness at any instant of time through mesh. In the current analysis, the central flat film thickness is found using the Grubin (1949) film thickness equation, including the side-leakage correction factor (Gohar, 2001): 


$$
h_{c 0} / R_{z x}=1.212\left(\alpha \eta_{0} U / R_{z x}\right)^{3 / 4}\left(W / E_{r} R_{z x}^{2}\right)^{-1 / 12}\left\{1+\frac{2}{3}\left(R_{z y} / R_{z x}\right)\right\}^{-2 / 3}
$$

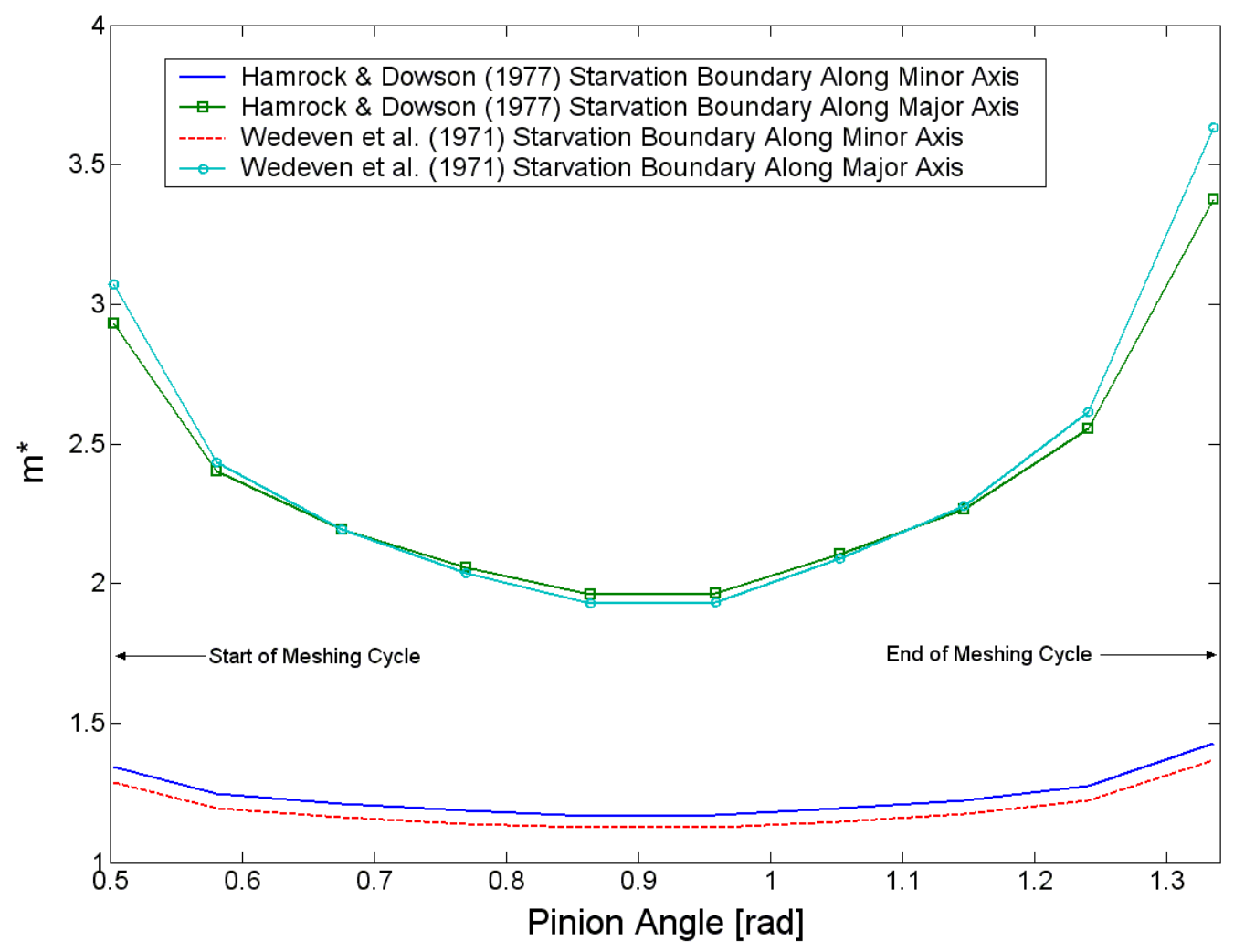

Figure 3: Inlet boundary for a teeth pair through mesh

The outlet boundary condition used is that of Swift (1932) - Stieber (1933): $p=\partial p / \partial x=0$ at $x=x_{c}$ and $p=\partial p / \partial y=0$ at $y=y_{c}$, where the film rupture positions, $x_{c}$ and $y_{c}$ are obtained by letting any negatively generated pressures to zero in the iterative numerical analysis.

\subsubsection{Method of solution of EHL problem and convergence Criteria}

Reynolds equation is discretised using finite differences in the same manner described by Jalali-Vahid et al (2000). Solution for pressure at any nodal position (i,j) with a computation grid covering the solution domain is based on low line relaxation effective influence NewtonRaphson method with Gauss-Seidel iterations, fully described by Jalali-Vahid et al (2000, 2001) and Ehret et al (1997).

The iterative process comprises the following steps:

1- At each pinion angle, $\varphi$ (commencing at the beginning of a meshing cycle), an initial guess is made for the central oil film thickness, using equation (9). The data for contact geometry, load and speed of entraining motion required for this purpose are obtained through TCA (section 2.2) 
2- Using the film thickness obtained in step 1, the inlet boundary condition is set as $m=m^{*}$ for both the inlet boundaries ahead of the major and minor axes of the Hertzian contact ellipse. Now a grid of $n_{x} \times n_{y}$ is used to cover the domain bounded by the inlet menisci along the $x$ (minor axis) and $y$ (major axis) and extend beyond the elliptical contact to include the conjunctional exit boundaries at the lubricant film rupture points; $x_{c}$ and $y_{c}$.

3- The pressure distribution and the corresponding lubricant film contour are obtained by simultaneous solution of equations (1)-(6) in an iterative manner, where two convergence criteria should be satisfied.

4- The first criterion seeks to compute nodal pressures within a specified limit:

$$
\sum_{i} \sum_{j}\left|\frac{p_{i, j}^{k}-p_{i, j}^{k-1}}{p_{i, j}^{k}}\right| \leq \varepsilon_{p}
$$

where, $10^{-5} \leq \varepsilon_{p} \leq 10^{-4}$. When the criterion is not satisfied, the generated pressures are under-relaxed as: $p_{i . j}^{k}=p_{i, j}^{k-1}+\Omega \Delta p_{i, j} \in i, j$. The under-relaxation factor is usually $0.01 \leq \Omega \leq 0.8$ and the steps 3-4 are repeated.

5- The second criterion seeks to converge the integrated pressure distribution (i.e. lubricant reaction, $W$ ) with the instantaneous load share of a contacting teeth pair through mesh, F. Recall that at any instant of time between 1-3 pairs of teeth are in simultaneous mesh in the case of the differential hypoid gear pair investigated here. The lubricant reaction is: $W=\iint p d x d y$. Thus, the load convergence criterion is: $\left|\frac{F-W}{F}\right| \leq \varepsilon_{w}$

where, $0.001 \leq \varepsilon_{w} \leq 0.05$. If the criterion is not met, the central film thickness $h_{c o}$ is adjusted and the entire iterative process; steps (3)-(5) are repeated:

$h_{c 0}^{l}=h_{c 0}^{l-1}\left(\frac{F}{W}\right)^{\varsigma}$

where, $-0.1 \leq \varsigma \leq 0.1$ is termed a damping factor.

In the above process, the indices $i, j$ refer to a computational grid position, $k$ denotes the pressure convergence iteration counter and $l$, the load convergence iteration counter.

6- When both the convergence criteria are met, the pinion angle is advanced within the meshing cycle and the entire process is repeated. To observe the contact conditions for any pair of meshing teeth, the meshing cycle is sub-divided into 10 discrete steps of the pinion angle rotation. 


\subsection{Tooth Contact Analysis (TCA)}

The geometrical, kinematics and load data required for the EHL analysis can be obtained from the TCA analysis.

The contact load per teeth pair is a function of the dynamic response of the system. However, its distribution among teeth pairs in simultaneous contact is defined quasi-statically. A load distribution factor is calculated as a function of the pinion angle for all such contacts. This is the ratio of the applied load $F_{i}$ on a given flank under consideration (figure 4) to the total transmitted load $F_{t}$ (Xu and Kahraman, 2007): If $=\frac{F_{i}}{F_{t}}$

A similar technique was followed for spur and helical gears by Vaishya and Singh (2001) and He et al (2007).

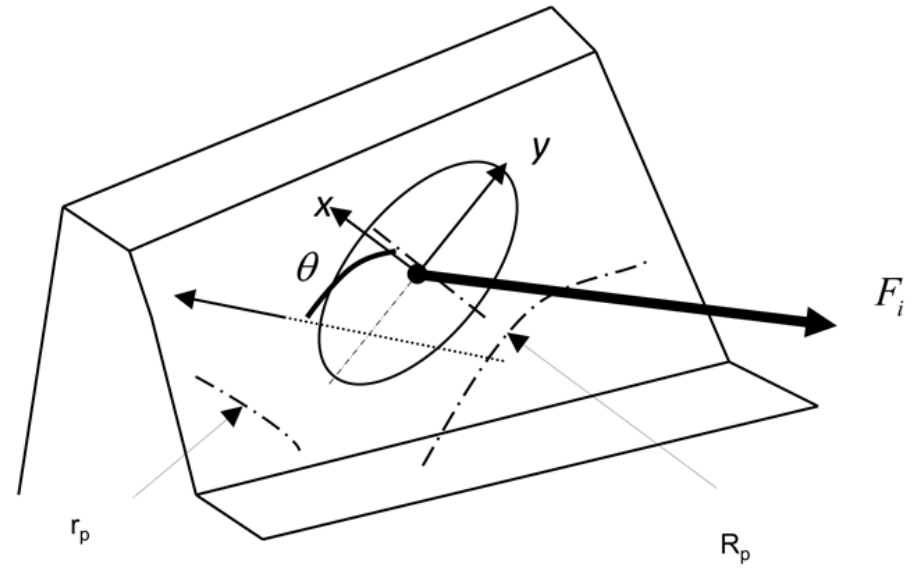

Figure 4: Contact footprint and direction of angled flow

The velocity of any point on the pinion and gear teeth in contact may be obtained as:

$v_{p}=\omega_{p}\left(n_{p} \times R_{\text {pin }}\right)$ and $v_{g}=\omega_{g}\left(n_{g} \times R_{\text {gear }}\right)$

$n_{p}$ and $n_{g}$ are the unit vectors along the pinion and gear axes respectively. $R_{p i n}$ and $R_{g e a r}$ are the position vectors of contact point with respect to the coordinate system attached to the axes of the pinion and the gear respectively. These velocities can be resolved along the normal direction $\left(v_{p}^{n}\right.$ and $\left.v_{g}^{n}\right)$ and along the tangential plane $\left(v_{p}^{t}\right.$ and $\left.v_{g}^{t}\right)$. The equality of the normal components is a non-holonomic constraint function for contact assurance: $\left|v_{p}^{n}-v_{g}^{n}\right|=0$. The tangential components can be used to obtain the rolling and sliding contact velocities. These components themselves can be presented as those along the major and minor axes of the Hertzian contact ellipse using vector dot products:

$v_{p}^{t, \text { major }}=v_{p} \bullet n_{\text {major }}, v_{g}^{t, \text { major }}=v_{g} \bullet n_{\text {major }}, v_{p}^{t, \text { minor }}=v_{p} \bullet n_{\text {minor }}$ and $v_{g}^{t, \text { minor }}=v_{g} \bullet n_{\text {minor }}$ 
where, $v_{p}^{t, \text { major }}$ and $v_{p}^{t, \text { minor }}$ are the components of pinion surface velocities along the major and minor axis. $v_{g}^{t \text {,major }}$ and $v_{g}^{t, m i n o r}$ are the components of gear surface velocities along the major and minor axis. $n_{\text {major }}$ and $n_{\text {minor }}$ are the unit vectors of the major and minor axis.

Thus, the speed of entraining motion along the minor and major axes of the elliptical footprint in equation (1) and figure 1 are obtained as:

$v_{r}^{\text {major }}=v_{p}^{t, \text { major }}+v_{g}^{t, \text { major }}=U \sin \theta$

$v_{r}^{\text {minor }}=v_{p}^{t, \text { minor }}+v_{g}^{t, \text { minor }}=U \cos \theta$

Clearly, the lubricant entrainment into the contact takes place at an angle to the minor axis of the Hertzian contact footprint:

$\theta=\tan ^{-1}\left(v_{r}^{\text {major }} / v_{r}^{\text {minor }}\right)$

The specifications for the face-hobbed and lapped hypoid gear pair in this study are listed in table 1a. Table $1 \mathrm{~b}$ provides the mechanical properties of the contacting surfaces and rheological properties of the lubricant. The results of contact kinematics are given in table 2 .

Table 1a: Gear pair parameters

\begin{tabular}{|l|l|}
\hline Pinion parameters: & \\
\hline Number of pinion teeth & 13 \\
\hline Pinion face-width (mm) & 33.851 \\
\hline Pinion face angle (deg) & 29.056 \\
\hline Pinion pitch angle (deg) & 29.056 \\
\hline Pinion root angle (deg) & 29.056 \\
\hline Pinion spiral angle (deg) & 45.989 \\
\hline Pinion pitch apex (mm) & -9.085 \\
\hline Pinion face apex (mm) & 1.368 \\
\hline Pinion Outer cone distance (mm) & 83.084 \\
\hline Pinion offset (mm) & 24.0000028 \\
\hline Pinion hand & Right \\
\hline
\end{tabular}

\begin{tabular}{|l|l|}
\hline Gear parameters: & \\
\hline Number of gear teeth & 36 \\
\hline Gear face width (mm) & 29.999 \\
\hline Gear face angle (deg) & 59.653 \\
\hline Gear pitch angle (deg) & 59.653 \\
\hline Gear root angle (deg) & 59.653 \\
\hline Gear spiral angle (deg) & 27.601 \\
\hline Gear pitch apex (mm) & 8.987 \\
\hline Gear face apex (mm) & 10.948 \\
\hline Gear Outer cone distance (mm) & 95.598 \\
\hline Gear offset (mm) & 24 \\
\hline
\end{tabular}


Table 1b: Properties of contacting solids and the Lubricant

\begin{tabular}{|l|l|}
\hline Pressure viscosity coefficient $(\alpha)$ & $2.6 \times 10^{-8}\left[\mathrm{~Pa}^{-1}\right]$ \\
\hline Atmospheric dynamic viscosity $\left(\eta_{0}\right)$ & $0.135[\mathrm{~Pa}-\mathrm{s}]$ \\
\hline Inlet density $\rho_{0}$ & $846\left[\mathrm{~kg} / \mathrm{m}^{3}\right]$ \\
\hline Modulus of elasticity of contacting solids & $210[\mathrm{GPa}]$ \\
\hline Poisson's ratio of contacting solids & $0.3[-]$ \\
\hline
\end{tabular}

Table 2: Equivalent geometry, Load share and kinematics of a teeth pair through mesh

\begin{tabular}{|c|c|c|c|c|c|c|}
\hline $\begin{array}{c}\text { pinion } \\
\text { angle } \varphi \\
(\mathrm{Rad})\end{array}$ & $\begin{array}{c}\text { Contact } \\
\text { load } F(\mathrm{~N})\end{array}$ & $\begin{array}{c}\text { Magnitude } \\
\text { of } \\
\text { entraining } \\
\text { velocity } \\
{[\mathrm{m} / \mathrm{s}]}\end{array}$ & $\begin{array}{c}\text { Velocity } \\
\text { along the } \\
\text { minor axis } \\
U \sin \theta \\
(\mathrm{m} / \mathrm{s})\end{array}$ & $\begin{array}{c}\text { Velocity } \\
\text { along the } \\
\text { major axis } \\
U \cos \theta \\
(\mathrm{m} / \mathrm{s})\end{array}$ & $\begin{array}{c}\text { Equivalent } \\
\text { radius } R_{z x} \\
(\mathrm{~m})\end{array}$ & $\begin{array}{c}\text { Equivalent } \\
\text { radius } R_{z y} \\
(\mathrm{~m})\end{array}$ \\
\hline 0.503 & 744.5 & 18.04 & 7.98 & 16.18 & 0.0157 & 1.0067 \\
\hline 0.581 & 1700.4 & 17.61 & 8.11 & 15.63 & 0.0160 & 1.0626 \\
\hline 0.675 & 2716.0 & 17.12 & 8.30 & 14.97 & 0.0164 & 1.1228 \\
\hline 0.770 & 3944.3 & 16.65 & 8.51 & 14.31 & 0.0168 & 1.1754 \\
\hline 0.864 & 5343.6 & 16.21 & 8.74 & 13.65 & 0.0174 & 1.2204 \\
\hline 0.958 & 5764.1 & 15.80 & 8.98 & 12.99 & 0.0180 & 1.2578 \\
\hline 1.052 & 4542.1 & 15.41 & 9.24 & 12.33 & 0.0186 & 1.2876 \\
\hline 1.147 & 3554.6 & 15.04 & 9.50 & 11.66 & 0.0194 & 1.3098 \\
\hline 1.241 & 2363.3 & 14.70 & 9.78 & 10.98 & 0.0202 & 1.3243 \\
\hline 1.335 & 939.2 & 14.39 & 10.06 & 10.29 & 0.0211 & 1.3313 \\
\hline
\end{tabular}

From table 2, it can be observed that significant lubricant entrainment occurs along the major axis of the contact ellipse. This side-leakage flow has a significant effect on film thickness and should not be ignored. This may be appreciated by fixing the direction of lubricant entrainment and noting the orientation of the elliptical contact footprint with respect to it as a pair of teeth progress through mesh (figure 5). The precession of the contact footprint with respect to the fixed lubricant velocity vector is as the result of combined rolling and sliding motion of teeth pair through mesh. The variation in the aspect ratio is as the result of instantaneous contact geometry, being approximately proportional to $\left(\frac{R_{z x}}{R_{z y}}\right)^{-2 / 3}$. Note that the side leakage correction factor obtained by Gohar (2001) is directly proportional to this ratio. This brief explanation shows that side leakage flow plays an important role because of the complex geometry of hypoid gears which promotes significant rolling and sliding motion. The size of the footprint is a function of the equivalent radii and the instantaneous load. 


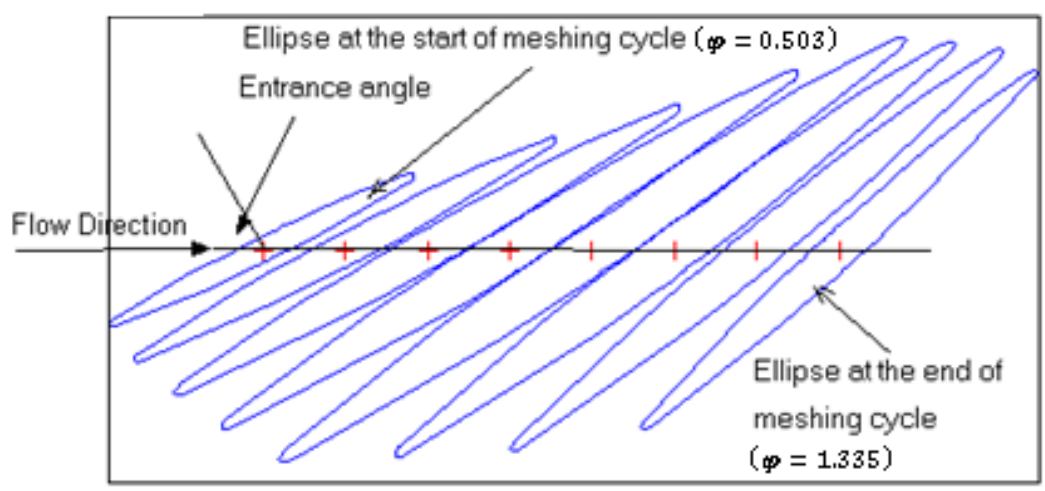

Figure 5: Instantaneous contact footprint orientation

\section{with respect to direction of lubricant entrainment}

\section{Results and Discussion}

The current analysis investigates the contact conditions for a pair of moderate to highly loaded hypoid gear pair of a light truck (tables 1 and 2). The results presented here correspond to the interaction of a typical gear teeth pair though a meshing cycle, during which between 1-3 teeth pairs carry the transmitted torque. The results correspond to an engine torque of $175 \mathrm{Nm}$ at $1852.5 \mathrm{rpm}$. The transmission is in $4^{\text {th }}$ gear with the ratio of 0.73:1.Table 2 lists the variation in the load share for a contacting teeth pair through mesh as well as the effective radii of curvature of an equivalent ellipsoidal solid contacting a semiinfinite elastic half-space of reduced elastic modulus $E_{r}$. Table 2 also lists the speed of entraining motion of the lubricant into the contact along the minor and major axes of the Hertzian elastostatic contact ellipse. These parameters constitute the input for the elastohydrodynamic analysis.

At any instant of time (at a given pinion angle) the contact domain is described by a computational mesh of $n_{x}$ by $n_{y}$ of $100 \mathrm{X} 100$ finite intervals. Simulation studies were carried out on a $2.93 \mathrm{GHz}$ Pentium Intel i7 machine with a total of $5173 \mathrm{CPU}$ seconds (86.2 min).

Figures 6 and 7 show the pressure distribution and the corresponding oil film thickness contours at the pinion angles $0.503 \mathrm{rad}$ (at the beginning of contact of a teeth pair) and at $0.958 \mathrm{rad}$, corresponding to the instant of maximum contact load (see table 2). The contour of minimum film thickness occurs at the exit constriction. Both cases show an asymmetrical oil film contour because of the angled lubricant flow into the contact with significant side leakage along the major axis of the elliptical footprint. Therefore, the island of minimum film thickness differs from the characteristic horse-shoe constriction when the flow is along the minor axis of the ellipse in EHL contacts of, for example, ball bearings. With a ten-fold increase in load, the film thickness is hardly altered, but the secondary pressure peak region is less pronounced and has moved further towards the exit constriction. These are typical characteristics of EHL contacts as noted by Evans and Snidle (1982) and Jalali-Vahid et al (2000) among others. 


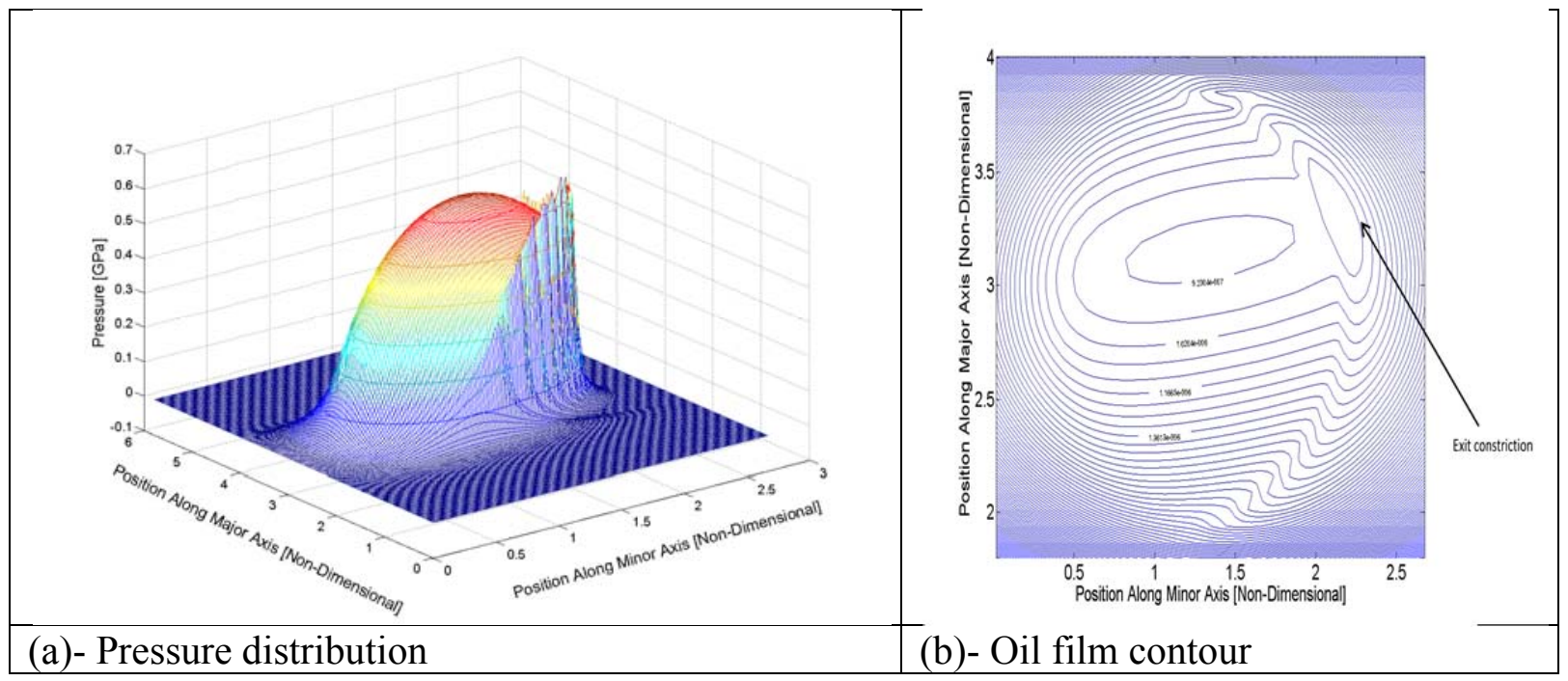

Figure 6: Pressure distribution and oil film contour at the beginning of teeth pair mesh with moderate load (pinion angle of 0.503 in Table 2)

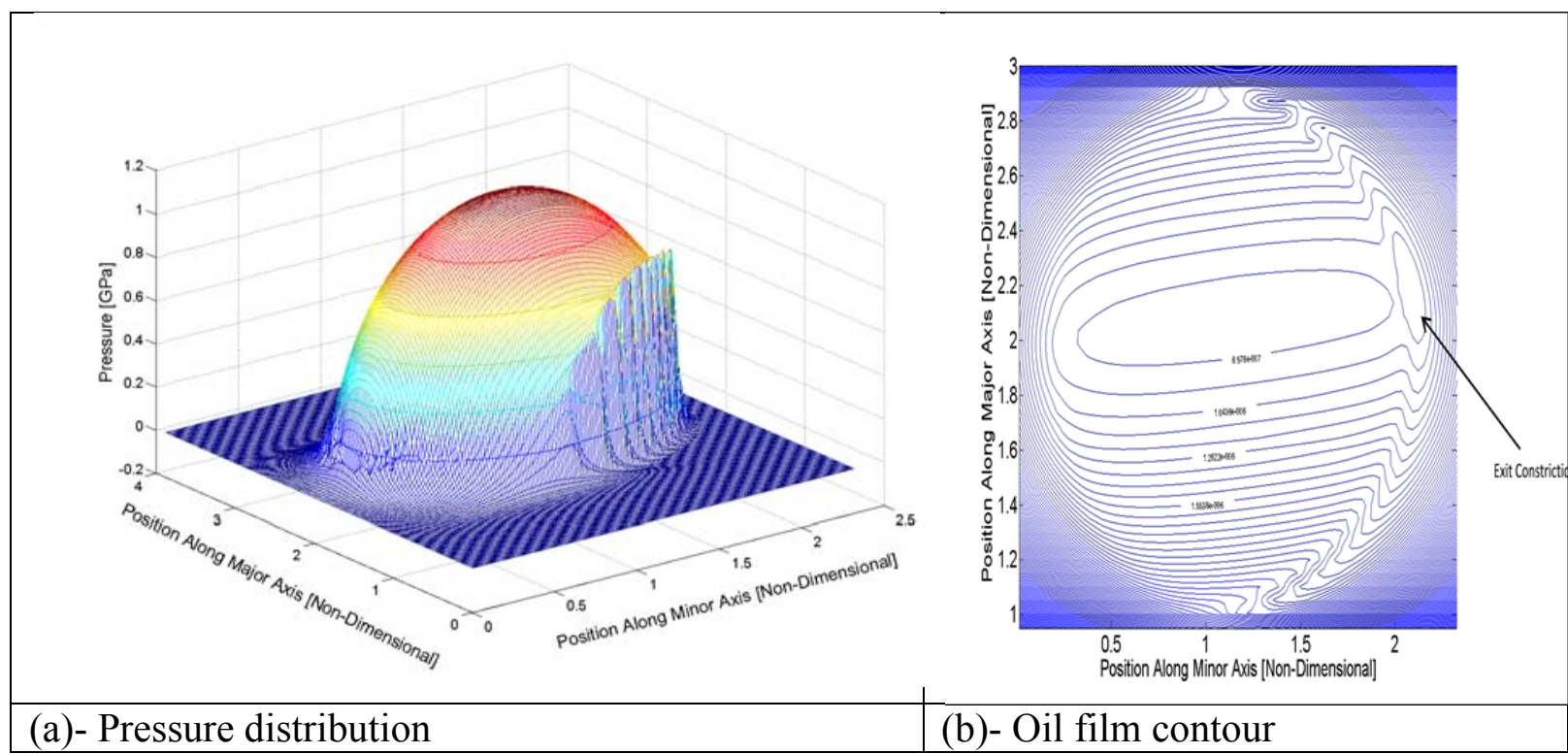

Figure 7: Pressure distribution and oil film contour at maximum contact load (pinion angle of 0.958 in Table 2)

A series of pressure profiles and the corresponding lubricant film thickness are shown in figure 8 during the meshing cycle. These show that EHL conditions prevail throughout the engagement of the teeth pair. Maximum pressures reached are around $1.2 \mathrm{GPa}$, even with loads of the order of $6 \mathrm{KN}$. This is because the hypoid gear pair teeth geometry is partially conforming, promoting a larger contact area than for example spur or helical gears. Thus, an assumed one dimensional solution would lead to prediction of much higher pressures than the case is in reality. As already noted the film thickness is almost unaffected by large variation in contact load. For the case presented here the minimum film thickness remains around $0.9-1.1 \mu \mathrm{m}$, which is well in excess of the composite root mean square surface roughness of the contiguous bodies in contact. The fairly thick minimum elastohydrodynamic films are due to high speed of entraining motion encountered in the reported application (see Table 2). The surface roughness of modern differential hypoid gear teeth which are ground and lapped are 
in the range 0.1-0.2 $\mu \mathrm{m}$ (Kolivand and Kahraman, 2010). With lower speeds of entraining motion and similarly high loads encountered here, worst tribological conditions are usually encountered. The results described here correspond to driving conditions that can often result in the axle whine phenomenon (Koronias et al, 2011). The isothermal solution here predicts no direct surface interactions. However, viscous shear of the lubricant generates heat, which reduces its effective viscosity. In many cases this reduces the film thickness and can promote mixed regime of lubrication (Xu et al, 2011).

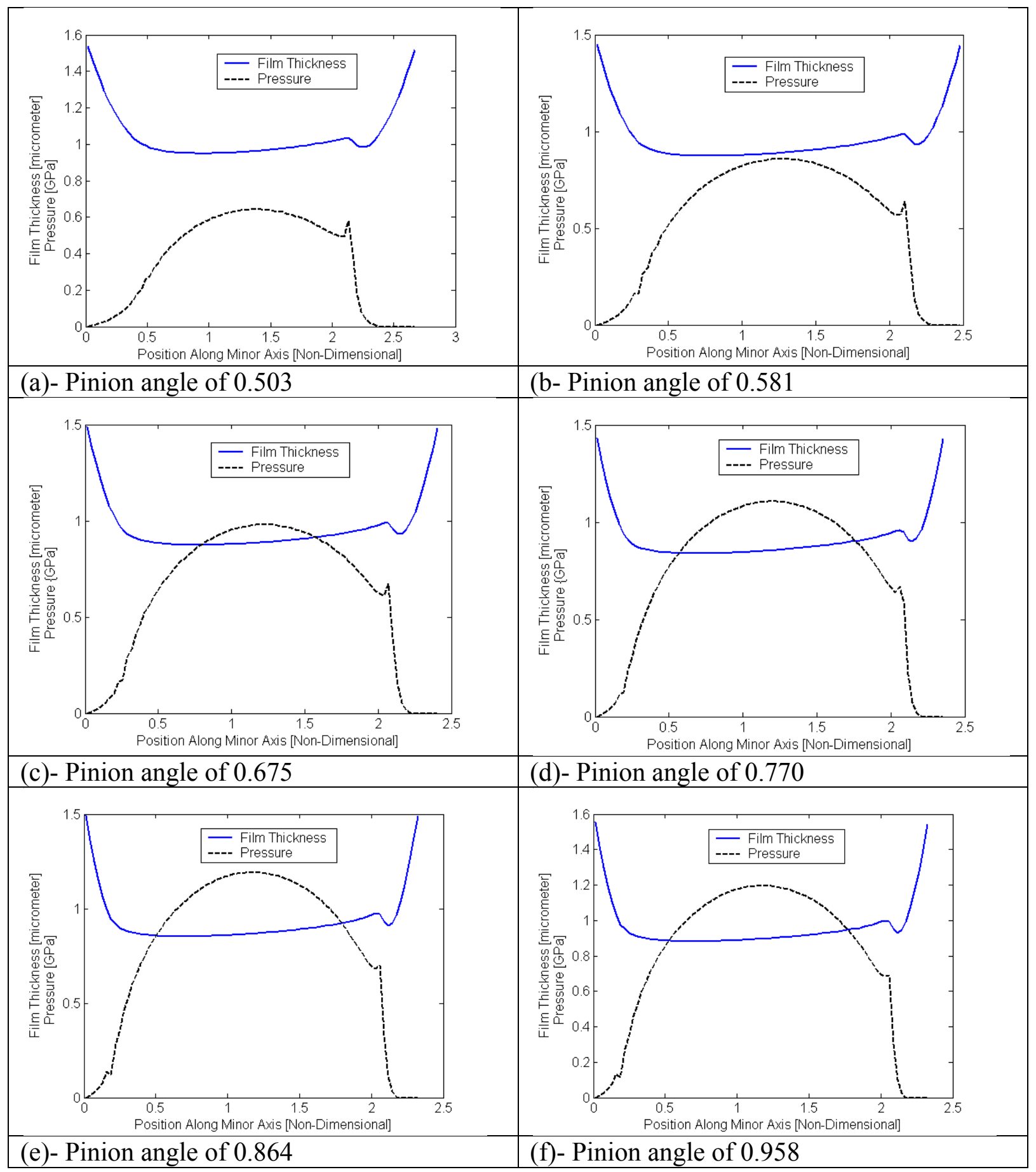




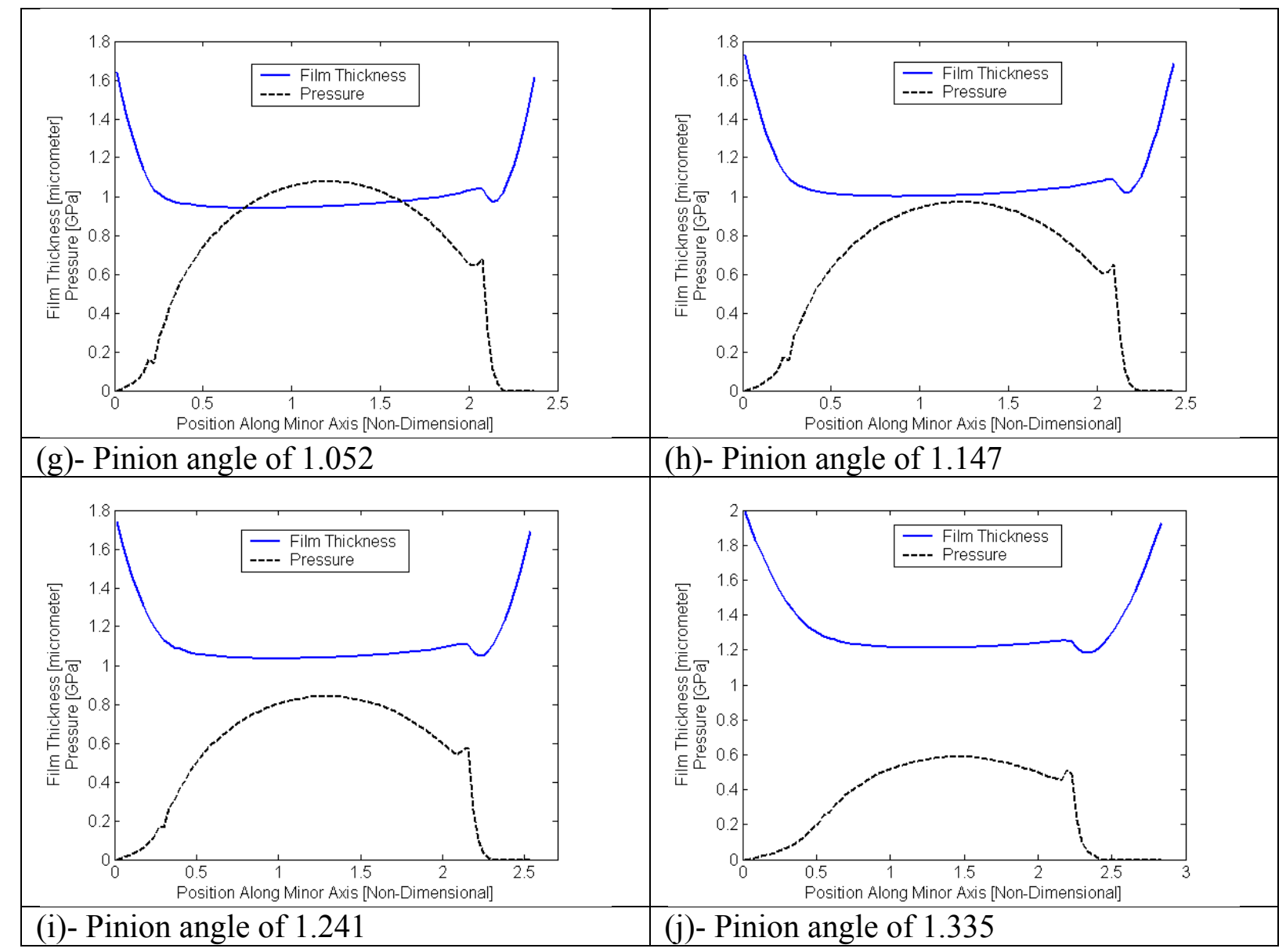

Figure 8: Pressure distribution and film thickness along the minor axis of the contact ellipse during a meshing cycle

Under elastohydrodynamic condition, the film thickness is mostly affected by the speed (or rolling viscosity) parameter, $U^{*}=\eta U \cos \theta / E_{r} R_{z x}$. This parameter attains its minimum value around the mid meshing cycle (pinion angle between 0.9-1 rad). Figure 9 shows the variation of predicted central and minimum film thickness values, both being around $0.9 \mu \mathrm{m}$. The figure also shows the predicted values from the Grubin equation (equation (9)) and those of Mostofi and Gohar (1982) and Chittenden et al (1985). These are:

For Mostofi and Gohar (1982):

$h_{m}^{*}=3.29 W^{*} G^{*}\left\{\left(\frac{U^{*}}{W^{* 3 / 2} G^{* 1 / 2}}\right)^{n}\left(W^{*} G^{* 3}\right)^{-\left(0.0707+0.0448 \cos ^{2} \theta\right)}\left(1-0.559 \cos ^{3} \theta\right)\right\}$

where: $h_{m}^{*}=\frac{h}{R_{z x}}, U^{*}=\frac{U \eta_{0}}{E_{r} R_{z x}}, W^{*}=\frac{W}{E_{r} R_{z x}^{2}}, G^{*}=E_{r} \alpha, n=0.649-0.0875 \cos ^{2} \theta$

And for Chittenden et al (1985): 


$$
\begin{aligned}
& h_{c 0}^{*}=4.31 U^{* 0.68} G^{* .49} W^{*-0.073}\left\{1-\exp \left[-1.23\left(\frac{R_{s}}{R_{e}}\right)^{2 / 3}\right]\right\} \\
& h_{m}^{*}=3.68 U^{* 0.68} G^{* 0.49} W^{*^{*}-0.073}\left\{1-\exp \left[-0.67\left(\frac{R_{s}}{R_{e}}\right)^{2 / 3}\right]\right\}
\end{aligned}
$$

where in this case:

$$
U^{*}=\frac{\pi \eta_{0} U}{4 E_{r} R_{e}}, W^{*}=\frac{\pi W}{2 E_{r} R_{e}^{2}}, G^{*}=\frac{2}{\pi}\left(E_{r} \alpha\right) \text { and } \frac{1}{R_{e}}=\frac{\cos ^{2} \theta}{R_{z x}}+\frac{\sin ^{2} \theta}{R_{z y}}, \frac{1}{R_{s}}=\frac{\sin ^{2} \theta}{R_{z x}}+\frac{\cos ^{2} \theta}{R_{z y}} .
$$

Whilst the predictions with the oil film thickness formulae follow similar trends (except marginally for that of Mostofi and Gohar, 1982) to the numerical predictions here, they actually over-estimate the film thickness. The over-estimation is because the equations do not apply to the ranges of load and speed parameters which are typical of differential hypoid gears. This is noted in the Introduction section, where similar differences were noted between the predictions with Mostofi and Gohar (1982) equation and the numerical results of Wildhaber-Novikov gears by Evans and snidle (1983). Another reason is that fully flooded condition, well beyond the starvation boundary, is implicit in the reported equations. In fact, it is generally thought that in practice most gearing systems are rather starved.

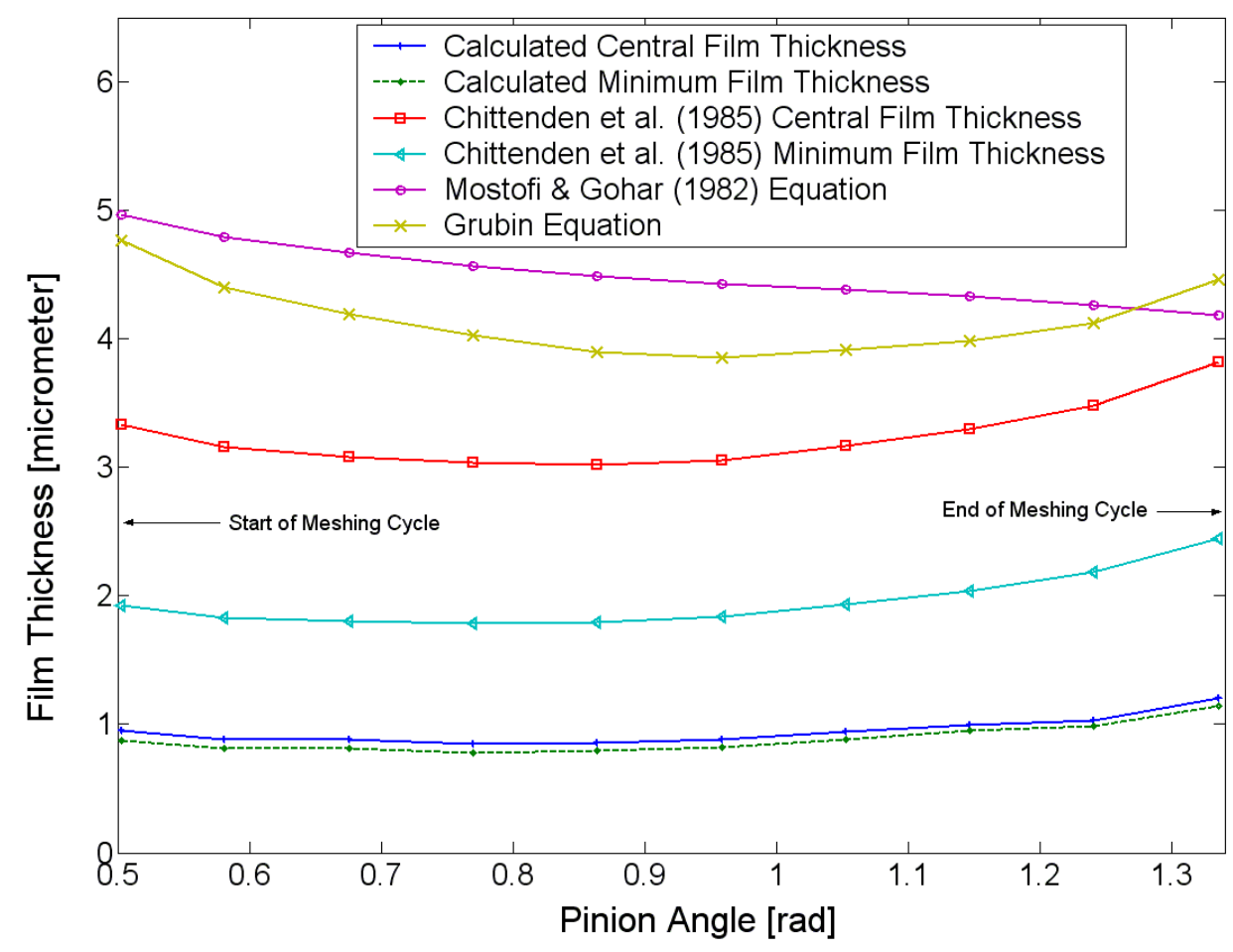

Figure 9: Comparative study of current analysis and those of reported film thickness equations 
Another point noted in the Introduction was the validity of assuming the lubricant flow along the minor axis of the contact ellipse. Figure 10 shows a comparison of an analysis with speed of entraining motion $U \cos \theta$ along the minor axis (same as Simon, 2009b) and that with the same condition in addition to side-leakage at the speed of $U \sin \theta$ along the major axis of the contact ellipse. Enhanced film thickness is noted due to increased volumetric flow into the contact area. Note that if the side-leakage flow is ignored the predicted film thickness is nearly halved. For ground gear teeth pairs with surface roughness of $0.2 \mu \mathrm{m}$, the composite surface roughness is $\sigma_{r m s}=0.28 \mu \mathrm{m}$. This means that the Stribeck (1907) oil film ratio, $\lambda=\frac{h_{m}}{\sigma_{r m s}} \approx \frac{0.4}{0.28}=1.43$ for assumed flow along the minor axis as opposed to $\lambda \approx 2.9$ when the flow along the major axis is also taken into account. Thus, the regime of lubrication tends to mixed-EHL when the side-leakage flow is ignored.

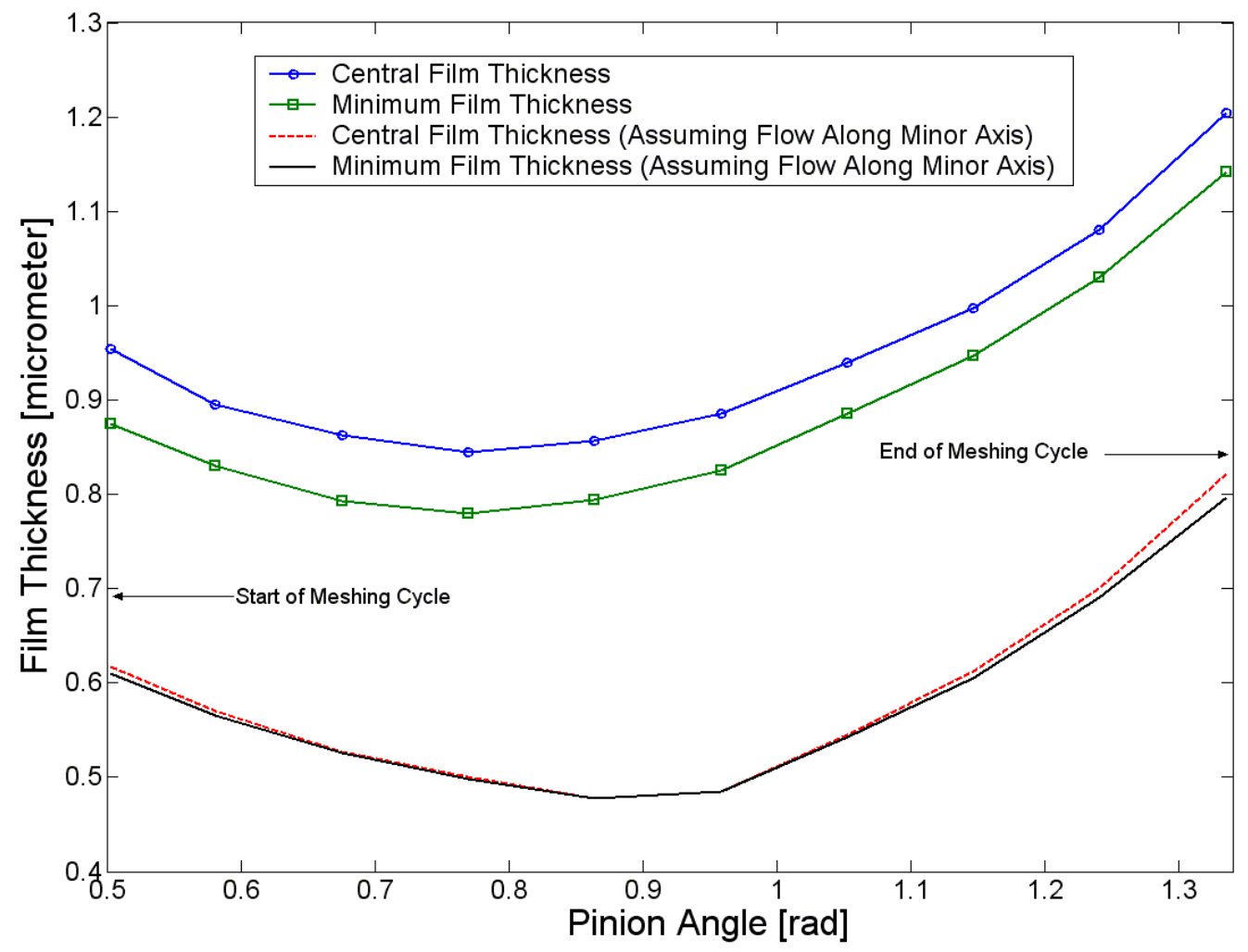

Figure 10: Film thickness during mesh with and without consideration of entrainment along the major axis of the contact ellipse

\section{4- Concluding Remarks}

The current analysis provides solution to the elliptical point contact problem for angled lubricant entrainment into the contact. It extends the original works of Chittenden et al (1985) and Jalali-Vahid et al (2000) to high contact loads experienced in meshing of differential hypoid gears. Whilst the works of Chittenden et al (1985) and Jalali-Vahid et al (2000) are 
quite generic, they do not apply to the case of hypoid gears as the requisite contact geometry is not obtained through tooth contact analysis as is the case in the current study. Realistic engine torque-speed characteristics are used, representative of light trucks in drive condition under steady state cruising. This extends the works of $\mathrm{Xu}$ and Kahraman (2007) who assumed a line contact geometry and that of Simon (2009b) who used the correct contact geometry but with very low torque, not representative of vehicle differential hypoid gears, as well as assuming lubricant entrainment along the minor axis of the Hertzian elliptical contact footprint only.

The current analysis shows that extrapolated oil film thickness equations reported in literature over-estimate the lubricant film thickness, because their underlying parametric studies do not extend to the contact conditions experienced for differential gear pairs. It is also shown that ignoring the flow along the major axis of the contact ellipse under-estimates the film thickness and predicts a change in regime of lubrication from elastohydrodynamics to mixedelastohydrodynamics. Such conditions may in fact be prevalent when friction and generated heat are considered. Therefore, a natural extension of this research is to include the solution of energy equation simultaneously with the current analysis. This approach constitutes the future direction of the current research. Another important consideration is to remove the non-holonomic contact assurance constraint $\left|v_{p}^{n}-v_{g}^{n}\right|=0$ and include the squeeze film effect in Reynolds equation and seek a solution based on pressure convergence only. This approach will yield transient EHL analysis.

\section{5- Acknowledgements}

Authors would like to express their gratitude to the Advanced Numerical Solutions Inc. for access to the TCA tool CALYX.

\section{6- References}

Archard, J.F. and Kirk, M.T. "Lubrication at point contacts", Proc. Roy. Soc., ser. A, 261, $532-550(1961)$

Archard, J.F. and Cowking, E.W. "Elastohydrodynamic lubrication at point contacts", Proc. Instn. Mech. Engrs., J. Mech. Engng. Sci., 180, 47-56 (1965)

Birkhoff, J. and Hays, D.F. "Free boundaries in partial lubrication", J. Math. \& Phys., 32, 2 (1963).

Cameron, A. and Gohar, R. "Theoretical and experimental studies of the oil film in lubricated point contacts", Proc. Roy. Soc., ser. A, 291, 520-536 (1966)

Cheng, H.S. "A numerical solution of the elastohydrodynamic film thickness in an elliptical contact”, Trans. ASME, J. Lubn. Tech., 92, 155-162 (1970)

Chittenden, R. J., Dowson, D., Dunn, J. F. and Taylor, C. M. "A theoretical analysis of the isothermal elastohydrodynamic lubrication of concentrated contacts. I. Direction of lubricant 
entrainment coincident with the major axis of the Hertzian contact ellipse“, Proc. Roy. Soc., Ser. A, 397, 245-269 (1985)

Chittenden, R. J., Dowson, D., Dunn, J. F. and Taylor, C. M. "A theoretical analysis of the isothermal elastohydrodynamic lubrication of concentrated contacts. II. General Case, with lubricant entrainment along either principal axis of the Hertzian contact ellipse or at some intermediate angle“, Proc. Roy. Soc., Ser. A, 397, 271-294 (1985)

De la Cruz, M., Theodossiades, S. and Rahnejat, H. "An investigation of manual transmission drive rattle”, Proc. Instn. Mech. Engrs., J. Multi-body Dyn., 224, 167-181 (2010)

Dowson, D. and Ehret, P. "Past, present and future studies in elastohydrodynamics", Proc. Instn. Mech. Engrs., J. Engng. Trib., 213, 317-333 (1999)

Dowson, D. and Higginson, G.R. "A numerical solution to the elastohydrodynamic problem”, Proc. Instn. Mech. Engrs., J. Mech. Engng. Sci., 1, 6-15 (1959)

Ehret, P., Dowson, D. and Taylor, C.M. "Time-dependent solutions with waviness and asperities in EHL Point Contacts", Proc. $23^{\text {rd }}$ Leeds-Lyon Sympos., Trib. Series, Elsevier, 32, 313-324 (1997)

Ertel, A.N. "Hydrodynamic lubrication based on new principles", Akad. Nauk. SSSR. Prikadnaya Mathematica i Mekhanika, 3(2), 41-52 (1939)

Evans, H.P. and Snidle, R.W. "The elastohydrodynamic lubrication of point contacts at heavy loads", Proc. Roy. Soc., ser. A, 382, 183-199 (1982)

Evans, H.P. and Snidle, R.W. "Analysis of elastohydrodynamic lubrication of elliptical contacts with rolling along the major axis", Proc. Instn. Mech. Engrs., J. MNech. Engng. Sci., 197, 209-211 (1983)

Grubin, A.N. " Contact stresses in toothed gears and worm gears", Book 30 CSRI for Technology and Mechanical Engineering , Moscow, DSRI Trans., 337 (1949)

Gohar, R. "Oil film thickness and rolling friction in elastohydrodynamic point contact", Trans. ASME, J. Lubn. Tech., 93, (1971)

Gohar, R. Elastohydrodynamics, Imperial College Press, London (2001)

Gohar, R. and Cameron, A. "Optical Measurement of Oil Film Thickness under Elastohydrodynamic Lubrication”, Nature, 200, 458-459 (1963)

Gohar, R. and Rahnejat, H. Fundamentals of Tribology, Imperial College Press, London (2008)

Hamrock, B.J. and Dowson, D. "Isothermal elastohydrodynamic lubrication of point contacts, Part I - Theoretical formulation", Trans. ASME, J. Lubn. Tech., 98, 223-229 (1976a) 
Hamrock, B.J. and Dowson, D. "Isothermal elastohydrodynamic lubrication of point contacts, Part II - Ellipticity parameter results”, Trans. ASME, J. Lubn. Tech., 98, 375-383 (1976b)

Hamrock, B.J. and Dowson, D. "Isothermal elastohydrodynamic lubrication of point contacts, Part IV - Starvation results”, Trans. ASME, J. Lubn. Tech., 99, 15-23 (1977)

He, S., Gunda, R. and Singh, R. "Inclusion of sliding friction in contact dynamics model for helical gears”, Trans. ASME, J. Mech. Des., 129, 48-57 (2007)

Jackson, A. Optical Elastohydrodynamics of Rough Surfaces, PhD Thesis, Imperial College, London (1973)

Jalali-Vahid, D., Rahnejat, H., Gohar, R. and Jin, Z.M. "Comparison between experiment and numerical solutions for isothermal elastohydrodynamic point contacts", J. Phys., D:

Appl. Phys., 31, 2725 (1998a)

Jalali-Vahid, D., Rahnejat, H. and Jin, Z.M. "Elastohydrodynamic solution for concentrated elliptical point contact of machine elements under combined entraining and squeeze-film motion", Proc. Instn. Mech. Engrs., J. Engng. Trib., 212, 401-411 (1998b)

Jalali-Vahid, D., Rahnejat, H., Gohar, R. and Jin, Z.M "Prediction of oil-film thickness and shape in elliptical point contacts under combined rolling and sliding motion", Proc. Instn.

Mech. Engrs., J. Engng. Trib., 214, 427-437 (2000)

Jalali-Vahid, D., Rahnejat, H., Jin, Z.M. and Dowson, D. "Transient analysis of isothermal elastohydrodynamic circular point contacts", Proc. Instn. Mech. Engrs., J. Mech. Engng. Sci., 215, 1159-1172 (2001)

Kolivand, M. and Kahraman, A. "A load distribution model for hypoid gears using ease-off topography and shell theory”, Mech. \& Mach. Theory, 44, 1848-1865 (2009)

Kolivand, M., Li, S. and Kahraman, A. "Prediction of mechanical gear mesh efficiency of hypoid gear pairs", Mech. \& Mach. Theory, 45, 1568-1582 (2010)

Koronias, G., Theodossiades, S. Rahnejat, H. and Saunders, T., "Axle whine phenomenon in light trucks: a combined numerical and experimental investigation", Proc. Instn. Mech. Engrs., Part D: J. Automobile Engng., 225, 885-894 (2011)

Litvin, F.L. and Fuentes, A. Gear Geometry and Applied Theory, Second ed., Cambridge University Press, New York (2004).

Litvin, F. L., Fuentes, A., Fan, Q. and Handschuh, R. F. “Computerized design, simulation of meshing, and contact and stress analysis of face-milled formate generated spiral bevel gears", Mech. \& Mach. Theory, 37, 441-459 (2002) 
Mehdigoli, H., Rahnejat, H. and Gohar, R. "Vibration response of wavy surfaced disc in elastohydrodynamic rolling contact”, Wear, 139, 1-15 (1990)

Mostofi, A. and Gohar, R. "Oil film thickness and pressure distribution in elastohydrodynamic point contacts”, Proc. Instn. Mech. Engrs., J. Mech. Engng. Sci., 24, 171-182 (1982)

Rahnejat, H. "Computational modelling of problems in contact dynamics", Engng.

Anal., 2, 192-197 (1985)

Rahnejat, H. and Gohar, R. "The vibrations of radial ball bearings", Proc. Instn. Mech. Engrs., J. Mrch. Engng. Sci., 199, 181-193 (1985)

Ranger, A.P., Ettles, C.M.M. and Cameron, A. "The solution of point contact elastohydrodynamic problem", Proc. Roy. Soc. Ser. A, 346, 227-244 (1975)

Reynolds, O. "On the Theory of Lubrication and Its Application to Mr. Beauchamp Tower's Experiments, Including an Experimental Determination of the Viscosity of Olive Oil", Proc. Roy. Soc. Lond., 40, 191-203 (1886)

Roeland, C.J.A., Correlation aspect of the viscosity-temperature-pressure relation of lubrication oils, PhD Thesis, Delft University of Technology, The Netherlands (1966)

Simon, V. "Head-cutter for optimal tooth modifications in spiral bevel gears", Mech. \& Mach. Theory, 44, 1420-1435 (2009a)

Simon, V. "Influence of machine tool setting parameters on EHD lubrication in hypoid gears”, Mech. \& Mach. Theory, 44, 923-937 (2009b)

Stieber, W. "Das schwimmlager: Hydrodynamische theorie des gleitlagers", VDI-Verlag (1933)

Stribeck, R. "Ball bearings for various loads", Trans. ASME, 29, 42-483 (1907)

Swift, H.W. "The atability of lubricating films in journal bearings", Minutes of the Proc., $J$. Instn. Civ. Engrs., 223, 267-288 (1932)

Vaishya, M., Singh, R. "Analysis of periodically varying gear mesh systems with Coulomb friction using Floquet theory”, J. Sound \& Vib., 243, 525-545 (2001)

Wedeven, L.D., Evans, D. and Cameron, A. "Optical analysis of ball bearing starvation", Trans. ASME, J. Lubn. Tech., 93, 349-363 (1971) 
Venner, C.H. and Lubrecht, A.A. "Multigrid techniques: a fast and efficient method for the numerical simulation of elastohydrodynamically lubricated point contact problems", Proc. Instn. Mech. Engrs., J. Engng. Trib., 214, 42-63 (2000a)

Vijayakar, S. CALYX Manual, Advanced Numerical Solutions Inc., Columbus, Ohio (2000).

Venner, C.H. and Lubrecht, A.A. Multilevel Methods in Lubrication, Tribology Series, Dowson, D. (Ed.), Elsevier Science, 37, Amsterdam, Netherlands (2000b)

Westlake, F.J. and Cameron, A. "Interferometric Study of Point Contact Lubrication", LeedsLyon Sympos., Elsevier Sci., 153-159 (1973)

$\mathrm{Xu}, \mathrm{H}$. and Kahraman, A. "Prediction of friction-related power losses of hypoid gear pairs", Proc. Instn. Mech. Engrs, J. Multi-body Dyn., 221, 387-400 (2007)

Xu, H., Singh, A., Maddock, D., Kahraman, A., Hurley, J., “Thermal Mapping of an Automotive Rear Drive Axle”, SAE International Journal of Engines, 4 (1), 888-901 (2011) 